\title{
Impacto del uso del suelo agropecuario sobre macroinvertebrados acuáticos en pequeñas quebradas de la cuenca del río La Vieja (Valle del Cauca, Colombia)
}

\author{
Lina Paola Giraldo ${ }^{1}$, Julián Chará ${ }^{1}$, María del Carmen Zúñiga ${ }^{1,2}$, Ana Marcela Chará-Serna ${ }^{1}$ \\ \& Gloria Pedraza ${ }^{1}$ \\ 1. Centro para la Investigación en Sistemas Sostenibles de Producción Agropecuaria - CIPAV, Carrera 25 \# 6-62 Cali, \\ Colombia; lina@cipav.org.co, julian@cipav.org.co, ana@cipav.org.co, gloria@cipav.org.co \\ 2. Universidad del Valle, Departamento de Biología, Grupo de Investigaciones Entomológicas, Cali, Colombia; \\ maczuniga@gmail.com
}

Recibido 12-XII-2013. Corregido 20-I-2014. Aceptado 13-II-2014.

\begin{abstract}
Agricultural land use impacts on aquatic macroinvertebrates in small streams from La Vieja river (Valle del Cauca, Colombia). The expansion of the agricultural frontier in Colombia has exerted significant pressure on its aquatic ecosystems during the last few decades. In order to determine the impacts of different agricultural land uses on the biotic and abiotic characteristics of first and second order streams of La Vieja river watershed, we evaluated 21 streams located between 1060 and $1534 \mathrm{~m}$ asl in the municipalities of Alcalá, Ulloa, and Cartago (Valle del Cauca, Colombia). Seven streams were protected by native vegetation buffers, eight had influence of coffee and plantain crops, and six were influenced by cattle ranching. Habitat conditions, channel dimensions, water quality, and aquatic macroinvertebrates were studied in each stream. Streams draining cattle ranching areas had significantly higher dissolved solids, higher phosphorus, higher alkalinity, higher conductivity, and lower dissolved oxygen than those covered by cropland and forests. Coarse substrates and diversity of flow regimes were significantly higher in cropland and protected streams when compared to streams affected by cattle ranching, whereas the percent of silt and slow currents was significantly higher in the latter. A total of 26777 macroinvertebrates belonging to 17 orders, 72 families and 95 genera were collected. The most abundant groups were Diptera 62.8\%, (Chironomidae 49.6\%, Ceratopogonidae 6.7\%), Mollusca 18.8\% (Hydrobiidae 7.2\%, Sphaeriidae 9.6\%) and Trichoptera 5.7\% (Hydropsychidae 3.7\%). The Ephemeroptera, Trichoptera, and Plecoptera orders, known for their low tolerance to habitat perturbation, had high abundance in cropland and forested streams, whereas Diptera and Mollusca were more abundant in those impacted by cattle ranching. Results indicate that streams draining forests and croplands have better physical and biological conditions than those draining pastures, and highlight the need to implement protective measures to restore the latter. Rev. Biol. Trop. 62 (Suppl. 2): 203-219. Epub 2014 April 01.
\end{abstract}

Key words: Andean streams, biomonitoring, aquatic insects, agriculture, pastures.

En las regiones tropicales se ha presentado una extensiva transformación del paisaje en las cuencas hidrográficas con consecuencias adversas para los ecosistemas acuáticos que se originan en ellas (Murgueitio \& Ibrahim, 2009). Entre los impactos negativos de esta tendencia se incluyen la destrucción de bosques ribereños, la contaminación del agua, la pérdida de regulación de caudales y la modificación de los cauces, entre otros (Chará, Pedraza \& Giraldo,
2009). Esta transformación, dada principalmente por actividades agropecuarias, rompe las relaciones estructurales y funcionales entre los elementos del paisaje y la estabilidad de los ambientes acuáticos (Schlosser, 1991; Piscart, Genoel, Doledec, Chauvet \& Marmonier, 2009; Riseng, Wiley, Black \& Munn, 2011).

Los procesos de trasformación se inician con la destrucción de bosques en los que posiblemente desaparecen muchas especies 
de plantas y animales (Laurence, Didham \& Power, 2001; Calle \& Piedrahita, 2008) y continúa con el cambio frecuente de sistemas productivos en los que predominan monocultivos, en especial de pasturas. Estas continuas transformaciones de cultivos y pasturas y el uso de agroquímicos ocasionan mayor perturbación del suelo y en la mayoría de los casos tienen consecuencias adversas para los ecosistemas (Chará et al., 2009). Un ejemplo se presenta en la cuenca del río La Vieja, enmarcada en el Eje Cafetero Colombiano, región que en los últimos años ha sufrido procesos acelerados de cambio de uso de suelo, pasando de cultivos de café a sistemas de producción ganadera (CARDER, 2007). En 1992 se desató una crisis para el sector cafetero, debido a la disminución de los precios del grano y la incidencia de la broca (Hypothenemus hampei). Esta situación causó la eliminación gradual de cafetales y la llegada de nuevos tipos de uso del suelo; entre 1992 y 1996 más de 14000 hectáreas de café fueron transformadas a pasturas y en menor proporción a plátano y otros cultivos (Sadeghian, Rivera \& Gómez, 1999).

La transformación del paisaje hacia monocultivos agrícolas y ganaderos en esta cuenca ha causado problemas de degradación del suelo, pérdida de diversidad y disminución de la calidad y cantidad de agua, especialmente en quebradas de primer y segundo orden (Chará, Pedraza, Giraldo \& Hincapié, 2007; Chará et al.,2009; Chará, Giraldo, Zúniga, CharáSerna \& Pedraza, 2011). La deforestación, la expansión de la agricultura y las pasturas, han contribuido a la desprotección total o parcial de las fuentes de agua y con ello han aumentado los problemas de erosión y contaminación en los ambientes acuáticos (Chará et al., 2011). En zonas ganaderas la deforestación afecta en forma negativa el hábitat de los macroinvertebrados acuáticos (Duehr \& Siepker, 2006; Lorion \& Kennedy, 2009). Sin embargo, en la cuenca del río La Vieja la información sobre el efecto que las actividades humanas tienen sobre los macroinvertebrados acuáticos aún es limitada. No obstante, se espera que tenga impactos negativos, ya que estudios en otras cuencas señalan a dichos organismos como sensibles a la contaminación y a cambios en el ambiente producto de efectos antropogénicos y por esto han sido propuestos como indicadores del estado de conservación de los ambientes acuáticos (Alba-Tercedor, 1996; Roldán, 2003; Bonada, Prat, Resh \& Statzner, 2006).

En la cuenca del río La Vieja, uno de los principales impactos relacionados con la producción ganadera y agrícola se da por la siembra de pasturas y cultivos hasta la orilla de las corrientes de agua. En las pasturas es frecuente que se permita el acceso del ganado a las quebradas para beber agua, con lo cual se sedimentan los cauces y se afecta la morfología del canal (Giraldo, Chará, Zúniga, Pedraza \& Chará-Serna, 2011). Además, las heces y la orina que son depositadas directamente en el agua y en el área de captación se suman a la aplicación de fertilizantes en los potreros y cultivos, contribuyendo al aumento de la concentración de nutrientes, materia orgánica y patógenos en el agua (Chará, 2004). Estos factores, junto con la disminución de caudales, el aumento de temperatura en el agua y la pérdida de estructura del hábitat, son efectos negativos comunes asociados a las actividades agropecuarias sobre las corrientes de agua (Allan, 2004).

Determinar cuál es el efecto específico de las actividades agropecuarias sobre los aspectos biofísicos de quebradas y los macroinvertebrados acuáticos en la ecorregión cafetera colombiana, es un paso fundamental para desarrollar medidas efectivas que resulten en la protección de estos importantes ecosistemas. Esta investigación se realizó con el fin de identificar el efecto del uso del suelo sobre el hábitat y la fauna béntica en quebradas pequeñas y establecer si los corredores de vegetación ribereña son efectivos en la protección de los mismos.

\section{MATERIALES Y MÉTODOS}

Área de estudio: La cuenca del río La Vieja se encuentra en el centro-occidente de Colombia en jurisdicción de los departamentos del Quindío, Risaralda y Valle del Cauca. Tiene una longitud aproximada de $53 \mathrm{~km}$ y es uno de 
los principales tributarios del río Cauca en su cuenca alta; cuenta con una extensión de 288 hectáreas distribuidas en 21 municipios y se subdivide en 23 subcuencas (Méndez \& Calle, 2010). El presente estudio se llevó a cabo en quebradas de primer y segundo orden ubicadas en la cuenca media del río La Vieja, en los municipios Alcalá, Ulloa y Cartago, en el norte departamento del Valle del Cauca. Las quebradas se localizaron en alturas desde 1060 hasta 1534 metros sobre el nivel del mar, entre las coordenadas $4^{\circ} 38^{\prime}-4^{\circ} 48^{\prime} \mathrm{N}$ y $75^{\circ} 43^{\prime}-75^{\circ} 53^{\prime} \mathrm{W}$.

Para la selección de las quebradas se tuvo en cuenta que fueran influenciadas solo por uno de los usos de suelo de interés en este estudio y que no estuvieran afectadas por descargas de aguas residuales de origen doméstico o agroindustrial.

Diseño del estudio: Se seleccionaron 21 quebradas para el estudio, siete de ellas protegidas por franjas de vegetación ribereña nativa con un ancho del corredor entre seis y $18 \mathrm{~m}$ a cada lado y con algún grado de perturbación ocasionada por extracción de madera y leña. Ocho quebradas presentaron influencia de agricultura, principalmente de cultivos de café y plátano, sembrados hasta la orilla de la quebrada y las seis quebradas restantes se encontraron en matrices de pasturas. El tipo de vegetación y el régimen de perturbación que presenta cada uno de los tipos de quebradas evaluadas se presentan en el Cuadro 1.

La selección de los tramos y la toma de información biofísica se llevó a cabo mediante la metodología descrita por Barbour, Gerritsen, Snyder \& Stribling (1999) adaptada para quebradas andinas por Chará (2004). En cada una de las quebradas se escogió un tramo representativo de $100 \mathrm{~m}$ de longitud, evitando que recibiera tributarios importantes y que estuviera influenciado por carreteras, puentes o cualquier obra que pudiera afectar las características del agua o el hábitat. Se realizó una caracterización general de cada microcuenca que incluyó información sobre tipo de vegetación, presencia de erosión, fuentes de contaminación, carreteras, cobertura de dosel y ancho del corredor ribereño.

En el mismo tramo de muestreo el hábitat fue caracterizado visualmente en cuanto a la composición relativa del sustrato (i.e., guijarros, grava, gravilla, arena, limo) y tipo de corriente (i.e., turbulencias, piscinas, y

\section{CUADRO 1}

Caracterización general de quebradas evaluadas con distintos usos de suelo en la cuenca del río La Vieja, Colombia

TABLE 1

General characteristics of evaluated streams with different land uses in La Vieja river watershed, Colombia

\begin{tabular}{|c|c|c|c|c|}
\hline $\begin{array}{l}\text { Uso de } \\
\text { suelo }\end{array}$ & Vegetación dominante & $\begin{array}{c}\text { Cobertura } \\
\text { del dosel }\end{array}$ & $\begin{array}{l}\text { Ancho de } \\
\text { corredor } \\
\text { ribereño }\end{array}$ & Régimen de perturbación \\
\hline Protegidas & $\begin{array}{l}\text { Árboles altos, arbustos y rastrojos bajos. } \\
\text { Bosques secundarios de guadua (Guadua } \\
\text { angustifolia), helechos arbóreos (Cyatheaceae) } \\
\text { y heliconias (Heliconia } \mathrm{sp} \text {.). }\end{array}$ & $>50 \%$ & $\begin{array}{c}6-18 \mathrm{~m} \text { a } \\
\text { cada lado }\end{array}$ & Extracción frecuente de madera y leña. \\
\hline Agrícolas & $\begin{array}{l}\text { Cultivos de café y plátano; algunos arbustos } \\
\text { y rastrojos bajos de ortiga (Urera spp), } \\
\text { cordoncillos (Piperaceae), bore (Xanthosoma } \\
\text { sagittifolium) y pastos de porte alto. }\end{array}$ & $<25 \%$ & $\begin{array}{c}<1 \mathrm{~m} \text { a } \\
\text { cada lado. }\end{array}$ & $\begin{array}{l}\text { Aplicación de abonos químicos a los } \\
\text { cultivos en el área de captación, aplicación } \\
\text { de herbicidas. Desyerbas constantes, } \\
\text { inestabilidad de las orillas de las quebradas, } \\
\text { erosión elevada. }\end{array}$ \\
\hline Ganaderas & $\begin{array}{l}\text { Pasturas- pasto estrella (Cynodon nlemfuensis). } \\
\text { En algunos casos árboles de matarratón } \\
\text { (Gliricidia sepium) como barreras vivas. }\end{array}$ & $\begin{array}{c}\text { Entre } \\
0-25 \%\end{array}$ & $0 \mathrm{~m}$. & $\begin{array}{l}\text { Aplicación de abonos químicos u orgánicos } \\
\text { a las pasturas en el área de captación. Libre } \\
\text { acceso del ganado a las quebradas para } \\
\text { consumir agua. Aplicación de herbicidas en } \\
\text { algunas áreas. }\end{array}$ \\
\hline
\end{tabular}


tramos de corriente lenta y rápida). Además, se tomaron medidas del cauce que incluyeron ancho del canal, ancho de la corriente, profundidad y caudal.

En cada quebrada se tomó una muestra puntual de agua para análisis fisicoquímico y bacteriológico, que incluyó los siguientes parámetros: $\mathrm{pH}$, sólidos totales, sólidos disueltos, demanda bioquímica de oxígeno $\left(\mathrm{DBO}_{5-20}{ }^{\circ} \mathrm{C}\right)$, oxígeno disuelto (OD), alcalinidad, conductividad, fósforo total, nitrógeno amoniacal, nitratos, coliformes fecales, coliformes totales. Las muestras fueron refrigeradas y transportadas para su análisis al laboratorio ambiental de la Corporación Autónoma Regional del Valle del Cauca- CVC, Cali. Los métodos analíticos utilizados corresponden a lo establecido en el Standard methods for the examination of water and wastewater (APHA, 2005).

Posterior a la toma de muestras fisicoquímicas y caracterización del hábitat, se recolectaron macroinvertebrados acuáticos utilizando una red tipo "D" con una abertura de malla de $500 \mu \mathrm{m}$, mediante 20 arrastres en los hábitats más representativos distribuidos en proporción a su ocurrencia. Las muestras biológicas fueron preservadas en campo con alcohol etílico al $80 \%$, posteriormente fueron separados e identificados en el laboratorio hasta el menor nivel taxonómico posible, con la ayuda de un estereoscopio (Nikon ${ }^{\circledR}$, Modelo SMZ 2T) con aumentos entre 10X y 40X y claves taxonómicas existentes para los diferentes grupos (Posada \& Roldán, 2003; Domínguez, Molineri, Pescador, Hubbard \& Nieto, 2006; Domínguez \& Fernández, 2009).

Análisis de la información: Debido a que las variables no siguieron una distribución normal, se usó la prueba de Kruskal Wallis, para determinar si existían diferencias significativas entre los tipos de usos de suelo para las diferentes características evaluadas en las 21 quebradas. Los análisis fueron realizados usando el programa Infostat versión 2008 (Di Rienzo et al., 2008).

Los macroinvertebrados recolectados fueron analizados calculando la riqueza de familias, de géneros y la abundancia absoluta y relativa de los principales taxones. Para las comparaciones de abundancia absoluta y relativa de órdenes y familias fueron excluidos Chironomidae (Diptera) y Mollusca por presentar abundancias muy altas que impedían observar patrones claros en el análisis de otros grupos. Los resultados obtenidos para dicha familia y phylum se presentan por separado. Se calculó el índice de biodiversidad de Shannon y el índice biótico BMWP-Univalle (Biological Monitoring Working Party). Este último fue adaptado por Zúñiga \& Cardona (2009) a cuerpos de agua del suroccidente colombiano.

Adicionalmente, se aplicó un análisis multivariado de gradiente directo con el objeto de describir la variación de la comunidad de macroinvertebrados de las quebradas evaluadas en términos de las variables ambientales. De acuerdo con la metodología propuesta por Leps \& Smilauer (2003), inicialmente se aplicó un análisis de correspondencias sin tendencia (Detrended Correspondence Analisis -DCA) para determinar la técnica de ordenación de gradiente directo más apropiada para los datos. Con este análisis, se estableció que los datos tenían la tendencia de responder de manera lineal, por lo que se utilizó el análisis de redundancia (Redundancy Analysis -RDA) para su ordenación. Los análisis multivariados fueron realizados con el programa Canoco para Windows Version 4.56 (Ter Braak \& Smilauer, 1997).

\section{RESULTADOS}

Parámetros fisicoquímicos y bacteriológicos: El Cuadro 2 resume las diferencias en los parámetros físicoquímicos y bacteriológicos en los tres usos del suelo y su nivel de significancia. Las quebradas en zonas ganaderas presentaron valores significativamente mayores (Kruskal Wallis, $\mathrm{p}<0.05$ ) de sólidos disueltos, alcalinidad, conductividad y fósforo total, que los otros dos grupos de quebradas. En contraste, la concentración de oxígeno disuelto fue significativamente menor en quebradas ganaderas que en quebradas con zona ribereña 
CUADRO 2

Parámetros fisicoquímicos y bacteriológicos en quebradas con distintos usos de suelo en la cuenca del río La Vieja, Colombia

TABLE 2

Water quality parameters in streams with different land use in La Vieja river watershed, Colombia

\begin{tabular}{|c|c|c|c|}
\hline Parámetro & $\begin{array}{l}\text { Quebradas protegidas } \\
\qquad(\mathrm{n}=7)\end{array}$ & $\begin{array}{c}\text { Quebradas con } \\
\text { influencia agrícola } \\
\qquad(\mathrm{n}=8)\end{array}$ & $\begin{array}{c}\text { Quebradas con } \\
\text { influencia ganadera } \\
\qquad(\mathrm{n}=6)\end{array}$ \\
\hline $\mathrm{pH}$ & $6.9 \pm 0.3$ & $7.0 \pm 0.2$ & $6.9 \pm 0.2$ \\
\hline Sólidos totales $\left(\mathrm{mgL}^{-1}\right)$ & $72.7 \pm 13.4$ & $92.8 \pm 19.5$ & $156.2 \pm 32.3$ \\
\hline Sólidos disueltos $\left(\mathrm{mgL}^{-1}\right)$ & $64.3 \pm 13.0^{\mathrm{a}}$ & $61.6 \pm 11.6^{\mathrm{a}}$ & $137.0 \pm 28.6^{b}$ \\
\hline $\mathrm{DBO}_{5-20^{\circ} \mathrm{C}}\left(\mathrm{mgL}^{-1} \mathrm{O}_{2}\right)$ & $0.5 \pm 0.1$ & $0.5 \pm 0.1$ & $0.7 \pm 0.2$ \\
\hline Oxígeno disuelto $\left(\mathrm{mgL}^{-1}\right)$ & $5.8 \pm 1.3^{b}$ & $5.7 \pm 0.8^{b}$ & $2.8 \pm 0.5^{\mathrm{a}}$ \\
\hline Alcalinidad total $\left(\mathrm{mgL}^{-1} \mathrm{CaCO}_{3}\right)$ & $31.4 \pm 6.3^{\mathrm{a}}$ & $30.7 \pm 3.6^{\mathrm{a}}$ & $86.5 \pm 20.4^{b}$ \\
\hline Conductividad $\left(\mu \mathrm{Scm}^{-1}\right)$ & $81.6 \pm 19.4^{\mathrm{a}}$ & $75.8 \pm 14.4^{\mathrm{a}}$ & $194.8 \pm 42.8^{b}$ \\
\hline Fósforo Total $\left(\mathrm{mgL}^{-1} \mathrm{PO}_{4}\right)$ & $0.1 \pm 0.0^{\mathrm{a}}$ & $0.1 \pm 0.0^{\mathrm{a}}$ & $0.2 \pm 0.0^{b}$ \\
\hline Nitrógeno amoniacal $\left(\mathrm{mgL}^{-1} \mathrm{~N}-\mathrm{NH}_{3}\right)$ & $0.6 \pm 0.1$ & $0.6 \pm 0.1$ & $0.6 \pm 0.1$ \\
\hline Nitratos $\left(\mathrm{mgL}^{-1} \mathrm{~N}-\mathrm{NO}_{3}\right)$ & $1.0 \pm 0.2^{\mathrm{a}, \mathrm{b}}$ & $1.7 \pm 0.3^{b}$ & $0.4 \pm 0.1^{\mathrm{a}}$ \\
\hline Coliformes totales (NMP. $100 \mathrm{~mL}^{-1}$ ) & $11348.6 \pm 4482.3$ & $40200 \pm 28792$ & $124800 \pm 51619.5$ \\
\hline Coliformes fecales (NMP. $100 \mathrm{~mL}^{-1}$ ) & $1165.7 \pm 436.4$ & $4290.0 \pm 2841$ & $45600 \pm 39039.7$ \\
\hline
\end{tabular}

Promedio \pm Error estándar, letras distintas indican diferencias significativas $(\mathrm{p}<0.05)$.

Average \pm standard error, Values with different letters indicate significant differences $(p<0.05)$.

protegida y quebradas en zonas agrícolas. Aunque no hubo diferencias significativas para los sólidos totales y coliformes totales y fecales, los valores promedio de estos parámetros fueron notablemente más altos en quebradas ganaderas y agrícolas que en las quebradas con zona ribereña protegida.

Caracterización del hábitat: Las variables asociadas a la morfología del cauce no presentaron diferencias significativas entre los usos de suelo evaluados (Cuadro 3). Sin embargo, las quebradas con influencia de ganadería mostraron tendencia a ser más anchas que las corrientes en zonas agrícolas o quebradas con zona ribereña protegida. En las quebradas ganaderas se encontró además menor caudal promedio que en las demás quebradas.

En las quebradas con influencia de ganadería casi la totalidad del sustrato estuvo conformado por limo, a diferencia de las quebradas protegidas por franjas de vegetación ribereña y quebradas en zonas agrícolas que presentaron una mayor diversidad de sustratos. El porcentaje de limo fue significativamente mayor (Kruskal Wallis, $\mathrm{p}<0.05$ ) y el de guijarro y grava significativamente menor (Kruskal Wallis, $\mathrm{p}<0.05$ ) en las quebradas ganaderas que en otros usos de suelo (Fig. 1).

En cuanto a los patrones de flujo, las quebradas con zona ribereña protegida y con influencia agrícola presentaron una diversidad de corrientes relativamente alta. Por otro lado, en las quebradas ganaderas el tipo de flujo predominante fue corriente lenta, que presentó porcentajes significativamente más altos que en los otros tipos de quebradas (Kruskal Wallis, $\mathrm{p}<0.05$ ) (Fig. 2).

Macroinvertebrados: En las 21 quebradas evaluadas, se recolectaron en total 26777 individuos, distribuidos en 17 órdenes, 72 familias y 95 géneros. La fauna estuvo representada principalmente por insectos acuáticos en estado inmaduro y adulto, y por otros grupos como Mollusca, Crustacea, Oligochaeta, Tricladida 
CUADRO 3

Características morfológicas del cauce en quebradas de la cuenca del río La Vieja, Colombia.

(Valores promedio y rangos)

TABLE 3

Channel measures in streams of La Vieja river watershed, Colombia (Mean values and ranges)

\begin{tabular}{lccc} 
Dimensiones del canal & Quebradas protegidas & $\begin{array}{c}\text { Quebradas con } \\
\text { influencia agrícola }\end{array}$ & $\begin{array}{c}\text { Quebradas con } \\
\text { influencia ganadera }\end{array}$ \\
Ancho húmedo $(\mathrm{cm})$ & $127.7(41-410)$ & $124.7(55-300)$ & $345.4(61-1330)$ \\
Profundidad $(\mathrm{cm})$ & $8.6(3-15.3)$ & $10.4(3-19.3)$ & $9.1(3.6-23.6)$ \\
Caudal $\left(\mathrm{Lseg}^{-1}\right)$ & $3.8(1.7-7.8)$ & $13.6(1-31.4)$ & $3.0(0.5-8)$ \\
\hline
\end{tabular}

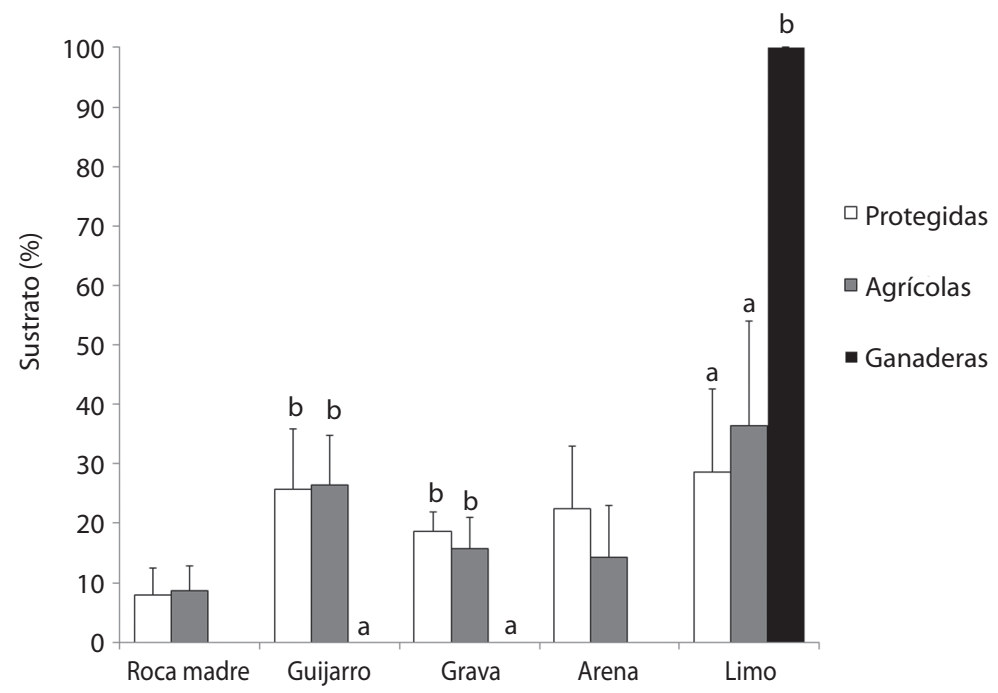

Fig. 1. Composición del sustrato en quebradas con distintos usos de suelo en la cuenca del río La Vieja, Colombia. (Líneas sobre las barras corresponden al error estándar). Letras distintas indican diferencias significativas ( $<<0.05)$.

Fig. 1. Substrate composition in streams with influence of different land uses in La Vieja river watershed, Colombia. Lines on the bars correspond to standard error). Bars with different letters indicate significant differences $(\mathrm{p}<0.05)$.

e Hirudinea (Fig. 3). Los grupos con mayor abundancia relativa en las 21 quebradas fueron Diptera 62.8\%, (Chironomidae 49.6\%, Ceratopogonidae 6.7\%), Mollusca $18.8 \%$ (Hydrobiidae $7.2 \%$, Sphaeriidae $9.6 \%$ ) y Trichoptera 5.7\% (Hydropsychidae 3.7\%).

En el Cuadro 4 se presentan algunas métricas calculadas para los grupos de quebradas evaluadas. Se encontraron diferencias significativa (Kruskal Wallis, $\mathrm{p}<0.05$ ) entre la abundancia absoluta promedio en quebradas con zona ribereña protegida (274.1) y quebradas en zonas ganaderas (2 543.1) y la riqueza de géneros en quebradas agrícolas, comparada con las demás. Aunque no hubo diferencias significativas entre las otras variables analizadas, las quebradas agrícolas y con zona ribereña protegida presentaron la mayor riqueza de géneros, mayor abundancia y porcentaje de EPT (sumatoria de Ephemeroptera, Plecoptera y Trichoptera) y el mayor puntaje para el índice BMWP-Univalle.

Excluyendo Mollusca, en las quebradas con zona ribereña protegida la mayor abundancia relativa se encontró en los órdenes Coleoptera (29\%), Trichoptera (26.5\%), Diptera (21.7\%) 


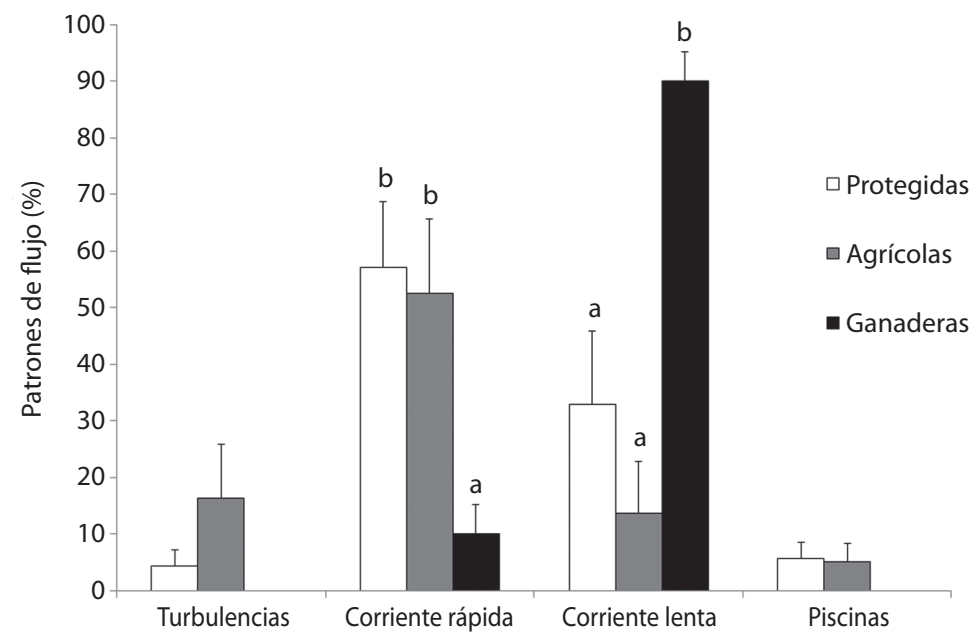

Fig. 2. Tipo de corriente en quebradas con influencia de tres usos de suelo en la cuenca del río La Vieja, Colombia. Líneas sobre las barras corresponden al error estándar, letras distintas indican diferencias significativas $(\mathrm{p}<0.05)$.

Fig. 2. Flow regimes present in streams with influence of different land uses in La Vieja river watershed, Colombia Lines on the bars correspond to the standard error). Bars with different letters indicate significant differences $(\mathrm{p}<0.05)$.

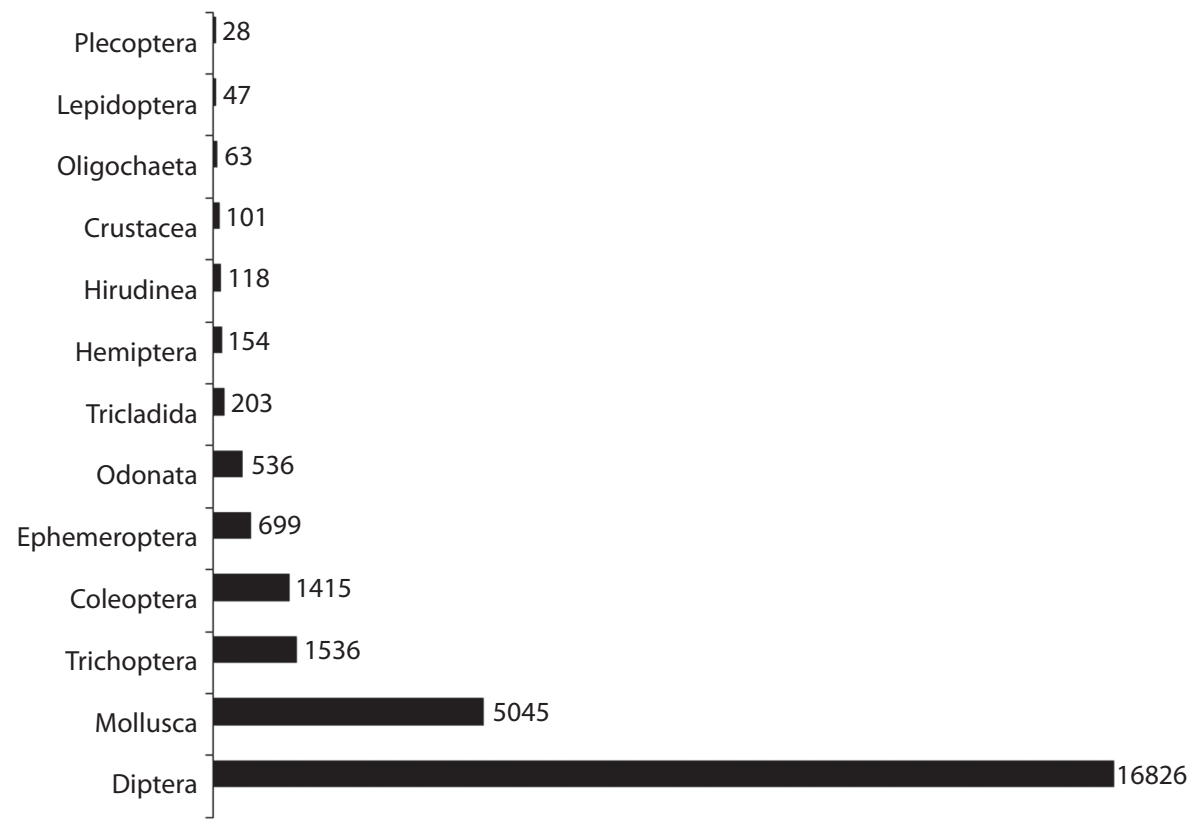

Fig. 3. Abundancia absoluta de macroinvertebrados acuáticos presentes en 21 quebradas de la cuenca del río La Vieja, Colombia.

Fig. 3. Absolute abundance of macroinvertebrates present in 21 streams of La Vieja river watershed, Colombia. 
CUADRO 4

Medidas estimadas con comunidad de macroinvertebrados de quebradas con influencia de distintos usos de suelo en la cuenca del río La Vieja, Colombia

TABLE 4

Macroinvertebrate assemblages metrics in streams with different land use in La Vieja river watershed, Colombia

\begin{tabular}{lccc}
\multicolumn{1}{c}{ Variable } & $\begin{array}{c}\text { Quebradas protegidas } \\
(\mathrm{n}=7)\end{array}$ & $\begin{array}{c}\text { Quebradas con influencia } \\
\text { agrícola }(\mathrm{n}=8)\end{array}$ & $\begin{array}{c}\text { Quebradas con influencia } \\
\text { ganadera }(\mathrm{n}=6)\end{array}$ \\
Abundancia promedio & $274,1^{\mathrm{a}}$ & $1199.6^{\mathrm{a}, \mathrm{b}}$ & $2543.5^{\mathrm{b}}$ \\
Riqueza de familias & 45 & 57 & 56 \\
Riqueza de géneros & $54^{\mathrm{a}}$ & $68^{\mathrm{b}}$ & $48^{\mathrm{a}}$ \\
Abundancia EPT & 561 & 1481 & 225 \\
\% EPT & 40.2 & 37.8 & 8.5 \\
Shannon H' & 2.9 & 2.9 & 1.2 \\
BMWP-Univalle & 92.1 & 128.6 & 82.5 \\
\hline
\end{tabular}

Valores con letras distintas indican diferencias significativas entre los usos de suelo $(\mathrm{p}<0.05)$.

Values with different letters indicate significant differences $(\mathrm{p}<0.05)$.

y Ephemeroptera (11.6\%). Para las quebradas agrícolas los órdenes más abundantes fueron: Diptera (37.4\%), Trichoptera (25.2\%), Coleoptera $(16.4 \%)$ y Ephemeroptera $(12.5 \%)$. Finalmente, en las quebradas ganaderas los órdenes con mayores abundancias relativas fueron: Díptera con $67 \%$ y Coleoptera con $14 \%$.

Se encontraron diferencias significativas para los órdenes Ephemeroptera y Trichoptera (Kruskal Wallis, $\mathrm{p}<0.05$; Cuadro 5), entre quebradas en zonas agrícolas y ganaderas. Por otro lado, aunque no hubo diferencias significativas para la abundancia de Díptera, se encontró un número mayor de estos organismos en quebradas ganaderas y agrícolas, que en quebradas con zona ribereña protegida.

Excluyendo Chironomidae y Mollusca, las familias con mayor porcentaje de individuos en las quebradas con zona ribereña protegida fueron Hydropsychidae (17.9\%), Elmidae (17.3\%) y Simuliidae (14.9\%); en las quebradas agrícolas las familias Simuliidae (29.1\%), Hydropsychidae (15.9\%) y Elmidae (11.4\%), $\mathrm{y}$ en las quebradas ganaderas Ceratopogonidae $(63.3 \%)$ y Libellulidae $(6.4 \%)$. La abundancia de Leptohyphidae, Leptophlebiidae, Hydropsychidae, Leptoceridae y Veliidae fue significativamente menor en quebradas con influencia de ganadería que en las quebradas con influencia de agricultura (Kruskal Wallis, $\mathrm{p}<0.05$; Cuadro 6). De igual manera, la abundancia absoluta de Ptilodactylidae, Philopotamidae, Gomphidae, Calopterygidae, Elmidae y Simuliidae fue significativamente menor (Kruskal Wallis, $\mathrm{p}<0.05$; Cuadro 6) en las quebradas ganaderas que en las quebradas con zona ribereña protegida o de zonas agrícolas.

Chironomidae: Entre los usos de suelos evaluados no se encontraron diferencias significativas en la abundancia de Chironomidae. Sin embargo, las quebradas ganaderas presentaron mayor número de individuos promedio (1216) que las quebradas en zonas de agricultura (698.5) y con zona ribereña protegida (58.4). La abundancia relativa de esta familia estuvo dada de la siguiente manera: quebrada agrícolas $58.2 \%$, ganaderas $47.8 \%$ y protegidas $21.3 \%$.

Mollusca: Las quebradas ganaderas presentaron mayor abundancia promedio de moluscos con 493.3 individuos, en las quebradas agrícolas y con zona ribereña protegida se recolectaron 5.6 y 5.4 individuos promedio, respectivamente. Se encontraron diferencias significativas (Kruskal Wallis, $\mathrm{p}<0.05$ ) para la familia Lymneidae y Planorbiidae en quebradas ganaderas, las cuales obtuvieron un mayor 
CUADRO 5

Abundancia absoluta de órdenes de macroinvertebrados presentes en quebradas con influencia de distintos usos de suelo en la cuenca del río La Vieja, Colombia (Promedio)

TABLE 5

Absolute abundance of macroinvertebrate taxones present in streams with different land use in the La Vieja River watershed, Colombia (Average)

\begin{tabular}{lccc}
\multicolumn{1}{c}{ Ordenes } & $\begin{array}{c}\text { Quebradas protegidas } \\
(\mathrm{n}=7)\end{array}$ & $\begin{array}{c}\text { Quebradas con influencia agrícola } \\
(\mathrm{n}=8)\end{array}$ & $\begin{array}{c}\text { Quebradas con influencia } \\
\text { ganadera }(\mathrm{n}=6)\end{array}$ \\
Ephemeroptera & $23.1^{\mathrm{a}, \mathrm{b}}$ & $61.3^{\mathrm{b}}$ & $7.8^{\mathrm{a}}$ \\
Plecoptera & 3.6 & 0.4 & 0.0 \\
Trichoptera & $52.9^{\mathrm{a}, \mathrm{b}}$ & $123.5^{\mathrm{b}}$ & $29.7^{\mathrm{a}}$ \\
Odonata & 12.3 & 27 & 39 \\
Coleoptera & 57.7 & 80.5 & 61.2 \\
Diptera* & 43.4 & 183.1 & 294.0 \\
\hline
\end{tabular}

* Sin Chironomidae.

Letras distintas indican diferencias significativas $(\mathrm{p}<0.05)$.

alues with different letters indicate significant differences $(\mathrm{p}<0.05)$.

número de organismos. En cuanto a las demás familias recolectadas, aunque no hubo diferencias significativas, la abundancia fue mayor en quebradas ganaderas que en las demás (Fig. 4).

\section{Relación entre los macroinvertebrados} y los ambientes: Los dos principales ejes del análisis de redundancia explicaron en conjunto el $46.5 \%$ de la variación de los datos (Fig. 5). El primer eje, que representó el 33\% de la variación en la composición de especies, estuvo principalmente determinado por la concentración de fósforo total, el porcentaje de corriente lenta, la concentración de oxígeno disuelto, el porcentaje de grava, el porcentaje de guijarros y la concentración de nitrógeno amoniacal; las primeras dos variables estaban directamente relacionadas con el eje, mientras que las siguientes presentaron una relación inversamente proporcional. El segundo eje que representó el $13.5 \%$ de la variación estuvo principalmente representado por el porcentaje de corriente rápida y el porcentaje de arena las cuales estaban inversamente relacionadas con dicho eje.

La Figura 5 muestra que las quebradas de zonas ganaderas se separaron de las quebradas con zona ribereña protegida y quebradas en zonas agrícolas por presentar mayores concentraciones de fósforo y mayores porcentajes de corriente lenta en el tramo. Las quebradas ganaderas también se caracterizaron por mayor abundancia de taxones como Sphaeriidae, Hydrobiidae, Glossiphonidae, Dugesidae e Hydrophilidae. Por otro lado, las quebradas agrícolas y con zona ribereña protegida fueron más similares entre sí en términos de composición de especies y características ambientales. Sin embargo, las quebradas con zona ribereña protegida mostraron tendencia a mayores concentraciones de nitratos, mayores porcentajes de corriente rápida y mayor porcentaje de arena y grava en el sustrato que las quebradas en zonas agrícolas.

Por su parte, las quebradas agrícolas presentaron mayores concentraciones de nitrógeno amoniacal, mayor concentración de oxígeno disuelto y mayores porcentajes de guijarro. En términos de composición de macroinvertebrados las quebradas agrícolas mostraron tendencia a presentar mayores abundancias de Simulium, Heterelmis y Anchytarsus que las fuentes con zonas ribereñas protegidas.

\section{DISCUSIÓN}

Este estudio sugiere que las actividades agropecuarias afectan en gran medida las 


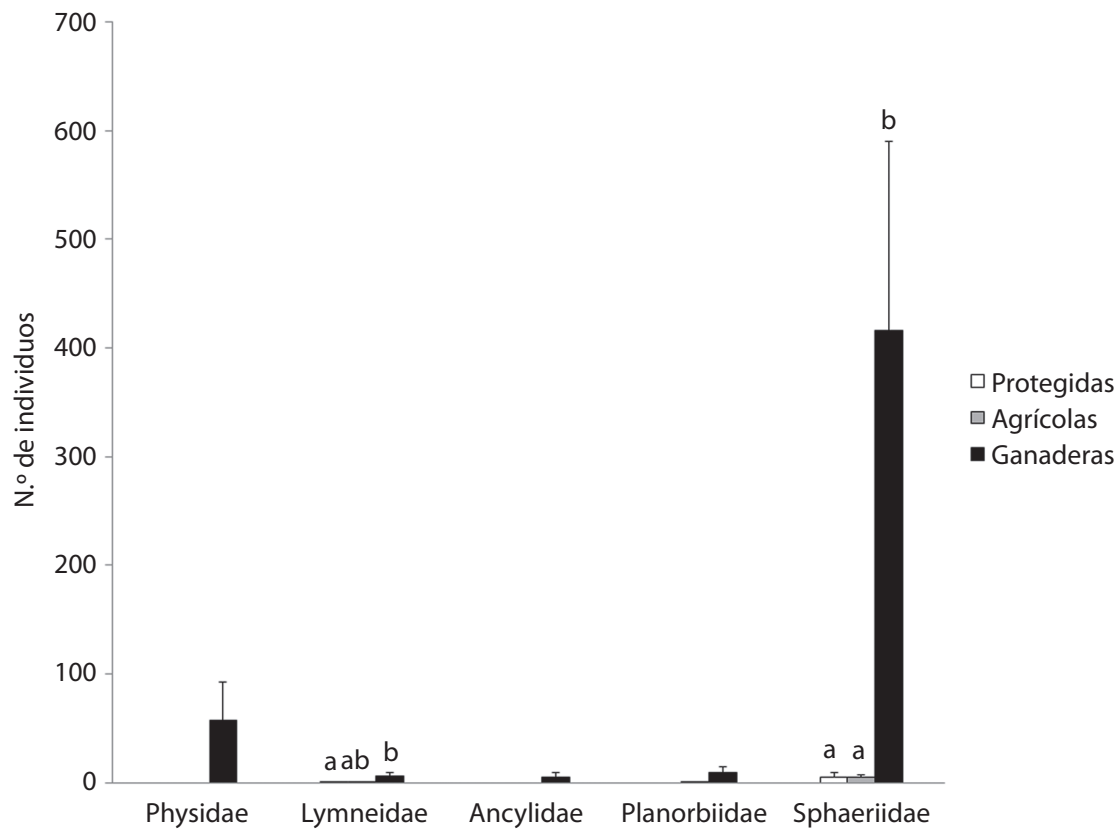

Fig. 4. Abundancia absoluta de Mollusca en quebradas con distintos usos de suelo en la cuenca del río La Vieja, Colombia (Líneas sobre las barras corresponden al error estándar). Letras distintas indican diferencias significativas $(\mathrm{p}<0.05)$.

Fig. 4. Absolute abundance of Mollusca in streams with different land use in La Vieja river watershed, Colombia (Lines on the bars correspond to the standard error). Different letters indicate significant differences $(\mathrm{p}<0.05)$.

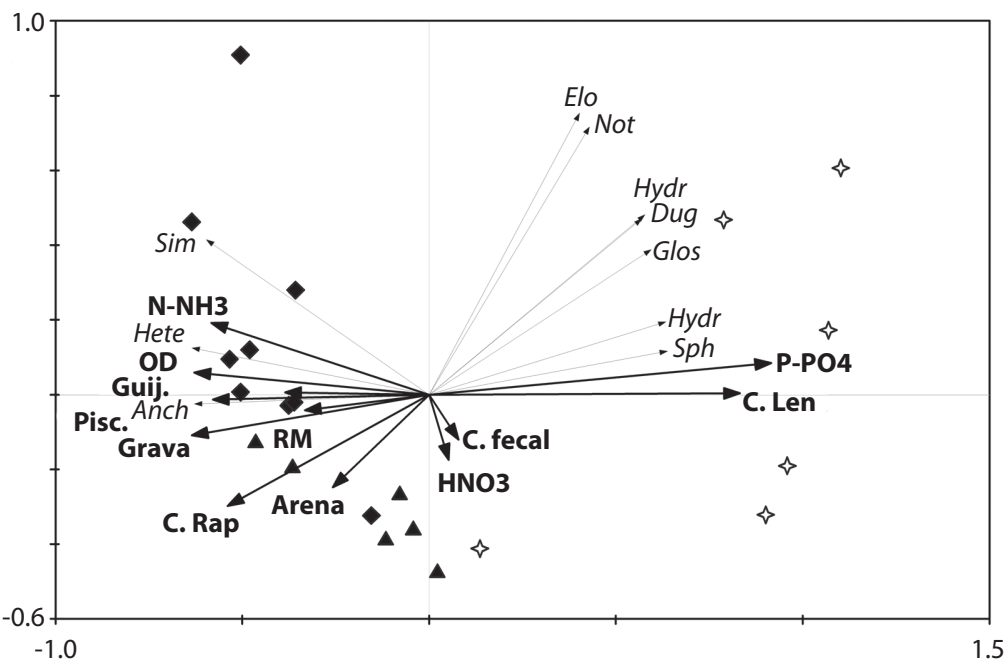

Fig. 5. Análisis de redundancia relacionando la composición de macroinvertebrados y las variables ambientales de las quebradas evaluadas en el estudio. Solo se muestran las variables que representan la mayor parte de la variación de los dos primeros ejes y los taxones con más relación a las mismas. Los símbolos representan quebradas ganaderas ( $\diamond)$, quebradas agrícolas $(\diamond)$ y quebradas protegidas $(\boldsymbol{\Delta})$.

Fig. 5. Redundancy analysis relating macroinvertebrate composition and environmental variables in the studied streams. Only variables explaining the greatest part of the variation in the first two axes and taxones with more relation with those variables are presented. Symbols represent streams in livestock areas $(\diamond)$, streams in agriculture area $(\diamond)$ and protected streams ( $(\boldsymbol{\Delta})$. 
CUADRO 6

Abundancia absoluta de familias* de macroinvertebrados representativas en quebradas de la cuenca del río La Vieja, Colombia (Promedio \pm Error estándar)

TABLE 6

Absolute abundance of representative macroinvertebrate families* in streams with different land use in La Vieja River watershed, Colombia (Average \pm Standard error)

\begin{tabular}{|c|c|c|c|}
\hline Familias & $\begin{array}{l}\text { Quebradas protegidas } \\
\qquad(\mathrm{n}=7)\end{array}$ & $\begin{array}{l}\text { Quebradas influencia agrícola } \\
\qquad(\mathrm{n}=8)\end{array}$ & $\begin{array}{l}\text { Quebradas influencia ganadera } \\
\qquad(\mathrm{n}=6)\end{array}$ \\
\hline Baetidae & $3.0 \pm 1.9$ & $13.0 \pm 6.0$ & $4.7 \pm 3.1$ \\
\hline Leptohyphidae & $12.6 \pm 7.9^{\mathrm{a}, \mathrm{b}}$ & $16.3 \pm 7.2^{b}$ & $0.2 \pm 0.2^{\mathrm{a}}$ \\
\hline Leptophlebiidae & $7.6 \pm 4.2^{\mathrm{a}, \mathrm{b}}$ & $31.8 \pm 10.9^{b}$ & $0.0 \pm 0.0^{\mathrm{a}}$ \\
\hline Helicopsychidae & $1.0 \pm 0.7$ & $3.3 \pm 1.9$ & $4.3 \pm 4.3$ \\
\hline Hydropsychidae & $35.6 \pm 22.2^{\mathrm{a}, \mathrm{b}}$ & $77.9 \pm 38.1^{b}$ & $21.7 \pm 18.4^{\mathrm{a}}$ \\
\hline Leptoceridae & $8.0 \pm 4.3^{\mathrm{a}, \mathrm{b}}$ & $34.0 \pm 12.4^{b}$ & $3.2 \pm 2.6^{\mathrm{a}}$ \\
\hline Philopotamidae & $1.4 \pm 0.5^{b}$ & $3.4 \pm 2.1^{b}$ & $0.0 \pm 0.0^{\mathrm{a}}$ \\
\hline Gomphidae & $4.1 \pm 2.1^{b}$ & $3.8 \pm 1.9^{b}$ & $0.0 \pm 0.0^{\mathrm{a}}$ \\
\hline Libellulidae & $2.1 \pm 0.6$ & $11.4 \pm 6.8$ & $28.2 \pm 21.1$ \\
\hline Calopterygidae & $1.9 \pm 0.6^{b}$ & $6.6 \pm 2.9^{b}$ & $0.0 \pm 0.0^{\mathrm{a}}$ \\
\hline Coenagrionidae & $2.1 \pm 1.4$ & $5.3 \pm 2.6$ & $10.0 \pm 5.1$ \\
\hline Veliidae & $2.4 \pm 1.1^{\mathrm{a}, \mathrm{b}}$ & $6.3 \pm 4.3^{b}$ & $0.2 \pm 0.2^{\mathrm{a}}$ \\
\hline Elmidae & $34.6 \pm 14.1^{b}$ & $56.0 \pm 18.1^{b}$ & $1.0 \pm 0.8^{\mathrm{a}}$ \\
\hline Noteridae & $0.0 \pm 0.0$ & $0.8 \pm 0.8$ & $19.3 \pm 14.8$ \\
\hline Ptilodactylidae & $22.0 \pm 7.8^{b}$ & $18.3 \pm 3.8^{b}$ & $0.2 \pm 0.2^{\mathrm{a}}$ \\
\hline Scirtidae & $0.1 \pm 0.1$ & $1.9 \pm 1.3$ & $9.2 \pm 3.9$ \\
\hline Ceratopogonidae & $1.0 \pm 0.8$ & $14.4 \pm 8.9$ & $278.5 \pm 275.3$ \\
\hline Simuliidae & $29.9 \pm 10.0^{b}$ & $142.5 \pm 72.9^{b}$ & $0.5 \pm 0.3^{\mathrm{a}}$ \\
\hline Stratiomyidae & $2.6 \pm 1.3$ & $6.5 \pm 4.1$ & $4.7 \pm 1.8$ \\
\hline Tipulidae & $8.3 \pm 4.0$ & $12.4 \pm 3.1$ & $4.0 \pm 2.5$ \\
\hline
\end{tabular}

* Sin Chironomidae

Letras distintas indican diferencias significativas $(\mathrm{p}<0.05)$.

Different letters indicate significant differences $(\mathrm{p}<0.05)$.

características bióticas y abióticas de pequeñas quebradas en la zona cafetera colombiana. Los valores más altos encontrados en quebradas ganaderas para parámetros fisicoquímicos y bacteriológicos que tienen que ver con la entrada de materia orgánica, nutrientes y sedimentos al cauce (p.ej., $\mathrm{DBO}_{5-20^{\circ} \mathrm{C}}$, fósforo total, sólidos disueltos, conductividad, coliformes fecales y totales), confirman que este uso de suelo afecta negativamente la calidad del agua de las quebradas. Por el contrario, la vegetación ribereña, bien sea en los bosques nativos o en cultivos permanentes como el café, ejerce una función protectora y contribuye a tener una mejor calidad del agua.

La similitud entre quebradas con zonas ribereña protegida y quebradas en zonas agrícolas (Fig. 5), demuestran que estos usos de suelo tienen menor impacto sobre los ambientes estudiados. Es importante recalcar que las quebradas con zona ribereña protegida tenían vegetación secundaria en el corredor ribereño con diferente grado de desarrollo y que los cultivos principales fueron café y plátano, considerados perennes y semi-perennes y con relativo alto uso de insumos en la zona, lo que puede aumentar la concentración de nutrientes.

Los resultados de este estudio son similares a los reportados por Chará et al. $(2007 ; 2011)$ y Giraldo et al. (2011), quienes en una zona ganadera de la misma cuenca, encontraron que las fuentes de agua que tenían zona ribereña protegida presentaban menores valores de turbidez, $\mathrm{DBO}_{5-20^{\circ} \mathrm{C}} \mathrm{y}$ coliformes que las quebradas sin 
protección por franjas de vegetación. De igual manera, en un estudio realizado por Thomas et al. (2004) en la Amazonía, encontraron que quebradas en zonas de pasturas presentaron menos oxígeno disuelto y mayores valores de sólidos en suspensión, nitrógeno amoniacal y fósforo total que quebradas en zonas boscosas.

Los datos bacteriológicos encontrados en el presente estudio coinciden también con los reportados por Collins (2003), quien encontró mayores valores de E. coli en quebradas con influencia de pasturas que en quebradas de zonas boscosas en Nueva Zelanda. Monaghan et al. (2009) encontraron también altos valores para $E$. coli y sólidos en suspensión en quebradas que drenan zonas de pasturas en Nueva Zelanda. Esta información apoya la idea de que los sistemas ganaderos generan una contaminación difusa importante y que las zonas ribereñas protegidas contribuyen a disminuir la entrada de estos contaminantes a las fuentes de agua.

La vegetación que crece en las orillas de las quebradas con zona ribereña protegida y quebradas en zonas agrícolas ejerce una función estabilizadora de los taludes. Las raíces de los árboles y arbustos protegen el suelo de la erosión y por ende mantienen la integridad del canal, lo que favorece además el establecimiento de estructuras que sirven como refugio y sustrato para la biota acuática y terrestre (Naiman, Decamps \& McClain, 2005). En las quebradas de zonas ganaderas, la remoción de la vegetación causa modificaciones físicas del cauce con el daño de los taludes, lo cual afecta la calidad del agua y la diversidad de hábitats para las comunidades biológicas (Sovell, Vondracek, Frost \& Mumford, 2000; Riseng et al., 2011). Aunque no se encontraron diferencias significativas para la morfología del cauce entre los usos de suelo evaluados, probablemente por la variabilidad de los datos, hubo una tendencia de las quebradas ganaderas a ser más anchas que las quebradas con zona ribereña protegida y quebradas en zonas agrícolas. Este mismo caso ha sido reportado por Baillie $\&$ Davies (2002), quienes proponen que el uso del suelo puede afectar la morfología del canal en quebradas pequeñas en Nueva Zelanda. Para la zona de estudio se pudo observar un impacto importante de la ganadería por erosión de los taludes o por perturbación del canal, tal y como lo reporta Wohl (2006) en otras zonas del mundo.

La diversidad de sustratos presente en las quebradas con zonas ribereñas protegidas demuestran que este uso de suelo favorece la estabilidad del cauce, contrario a lo reportado en quebradas de zonas ganaderas donde el libre acceso del ganado al cauce, además de destruir los taludes, genera entrada directa de sedimentos y escorrentía del área de captación (Herbst, Bogan, Roll \& Safford, 2012). Los sedimentos se acumulan en el fondo de la quebrada uniformizando el canal y cubriendo los espacios entre piedras que sirven de hábitat para organismos como peces y macroinvertebrados (Nakamura \& Yamada, 2005; Braccia \& Voshell, 2006; Chará et al., 2009; 2011; Giraldo et al., 2011). Otros estudios también han encontrado mayor cantidad de sedimentos en quebradas con pasturas, que en quebradas protegidas (HeartsillScalley \& Aide, 2003).

La mayor diversidad de organismos encontrados en las quebradas con zona ribereña protegida y las ubicadas en zonas de agricultura, está relacionado en parte con la mayor variedad de sustratos presente en estas quebradas, y con los aportes de ramas, hojarasca y el soporte de las raíces dado por los árboles. Las quebradas pequeñas y las zonas ribereñas proveen hábitat único para diferentes organismos (Moore \& Richardson, 2003). El aporte de hojarasca y ramas de la vegetación de esta zona, se constituyen en elementos muy importantes para la colonización de nuevos organismos. La eliminación de los árboles del área ribereña por la deforestación, agricultura y entrada del ganado reduce la profundidad, los sustrato gruesos y piscinas dentro del cauce (Wohl, 2006; Baillie \& Davies, 2002). La heterogeneidad y disponibilidad del sustrato es uno de los parámetros más relacionados con la variación en la composición de comunidades acuáticas (Richards \& Host, 1994; Collier, Wilcock \& 
Meredith, 1998; Bücker, Sondermann, Frede \& Breuer, 2010).

La mayor diversidad de flujos y las diferencias significativas encontradas para el porcentaje de corrientes lentas y rápidas en las quebradas con zona ribereña protegida y quebradas en zonas agrícolas con respecto a las ganaderas, confirma que las características físicas de las corrientes de agua que fluyen en matrices de pasturas son afectadas negativamente por este uso de suelo. El pastoreo en las zonas ribereñas puede compactar el suelo, reducir la infiltración e incrementar la corriente, la erosión, los sedimentos y los nutrientes dentro de los cauces (Nakamura \& Yamada, 2005; Herbst et al., 2012). Los macroinvertebrados y peces sensibles a la perturbación del hábitat pueden verse afectados por el incremento de los nutrientes y sedimentos en el cauce. Cuando son eliminados los obstáculos dentro de las quebradas como piedras, hojarasca, troncos, o cuando son colmatadas las charcas con sedimento, tiende a prevalecer sólo un tipo de corriente, como es el caso de las quebradas ganaderas que presentaron predominancia de corriente lenta. Esto mismo ha sido reportado por Chará et al. (2007) para quebradas de la misma región y por Hall, Closs \& Riley (2001), quienes encontraron menor velocidad del agua en quebradas con influencia de agricultura en Nueva Zelanda.

En cuanto a macroinvertebrados, los tres órdenes de insectos (Diptera, Trichoptera, Coleoptera) mejor representados en el conjunto de quebradas evaluadas se han reportado como los grupos más abundantes en quebradas de bajo orden en otros estudios (Posada, Roldán \& Ramírez, 2000; Quinn, Boothroyd \& Smith, 2004; Winckler-Sosinski, Silveira, Schulz \& Schwarzbold, 2008). Las quebradas en zonas agrícolas y ganaderas presentaron la mayor abundancia y la mayor riqueza de familias. Sin embargo, las quebradas ganaderas obtuvieron menor diversidad, riqueza de géneros y puntaje para el índice BMWP-Univalle, lo que indica que la alta abundancia es determinada por organismos indicadores de calidad de agua regular. De acuerdo a los valores obtenidos para cada uso de suelo, las quebradas con zona ribereña protegida y agrícolas se ubican en aguas de calidad buena y las quebradas ganaderas en el grupo de aguas de calidad aceptable (Roldán, 2003; Zuñiga \& Cardona, 2009).

La mayor abundancia de organismos pertenecientes a órdenes sensibles a la perturbación del hábitat, tales como Ephemeroptera y Trichoptera, en las quebradas agrícolas y con zona ribereña protegida, confirman que existen mejores condiciones de calidad del agua y calidad del hábitat en estos ambientes que en las quebradas con influencia de ganadería (Gamboa, Reyes \& Arrivillaga, 2008). Otros trabajos corroboran que estos grupos son más representativos en quebradas protegidas por corredores ribereños, que cuando son afectados por cualquier otro uso del suelo (Harding, Benfield, Bolstad, Helfman \& Jones, 1998; Hall et al., 2001; Moya, Oberdorff, Bigorne, Zubieta \& Camacho, 2006; Lorion \& Kennedy, 2009; Miserendino \& Masi, 2010).

Para el orden Plecoptera, si bien se encontró mayor abundancia en las quebradas protegidas por franjas de vegetación ribereña, la diferencia no fue significativa. Esta situación presumiblemente se deba a que aún las quebradas consideradas como protegidas en este estudio tienen un grado de perturbación importante que puede afectar a este orden propio de aguas rápidas, turbulentas, frías y altamente oxigenadas (Domínguez \& Fernández, 2009; Stark, Froehlich \& Zúniga, 2009; Zúñiga, 2010).

Aunque no se encontraron diferencias significativas para la familia Chironomidae entre los usos de suelo evaluados, hubo mayor abundancia de estos organismos en las quebradas de zonas ganaderas y agrícolas. Para los moluscos, todas las familias reportadas en este estudio se encontraron en las quebradas de zonas ganaderas, a diferencia de las quebradas con zona ribereña protegida y zona agrícolas que presentaron solo dos de las cuatro familias recolectadas. La familia Chironomidae y el phylum Mollusca se encuentran con mayor abundancia en ambientes acuáticos donde el sustrato está conformado por sedimentos finos (Fig. 5) y donde hay presencia de abundante materia orgánica (Posada 
et al., 2000; Roldán, 2003). Otros estudios han reportado mayor presencia de moluscos y Chironomidae en quebradas desprotegidas (Hall et al., 2001; Moya et al., 2006; Lorion \& Kennedy, 2009).

Los resultados de este estudio confirman que los sistemas ganaderos ejercen la mayor presión negativa sobre pequeñas quebradas en la cuenca del río La Vieja. Lo anterior es demostrado por el mayor deterioro de la calidad de agua, y de las características físicas del hábitat como tipo de corriente y tipos de sustrato. La degradación del hábitat es además corroborada con la fauna béntica reportada para este uso de suelo, que en su mayoría se asocia a ambientes acuáticos degradados.

Por el contario, la vegetación nativa del área ribereña en las quebradas protegidas, a pesar de la intervención que presenta, ejerce funciones muy importantes para la protección de características físicas dentro del cauce. Las comunidades de macroinvertebrados acuáticos no se ven afectadas por el daño físico del hábitat y baja calidad del agua; por esta razón deben ser planteados como estrategias para disminuir los efectos de prácticas agropecuarias en el área de captación de las quebradas.

\section{AGRADECIMIENTOS}

Agradecemos a la Corporación Autónoma Regional del Valle del Cauca (CVC) por su apoyo logístico y los análisis de laboratorio realizados mediante los convenios CVC-CIPAV 202 de 2002 y CVC-CIPAV 056 de 2005. Al Laboratorio de Investigaciones Entomológicas de la Universidad del Valle por su apoyo en la determinación de los macroinvertebrados bentónicos recolectados en la zona de estudio. Además se contó con el apoyo del Departamento Administrativo de Ciencia, Tecnología e Innovación, COLCIENCIAS, por el Patrimonio Autónomo Fondo Nacional de Financiamiento para la Ciencia, La Tecnología y la Innovación, Francisco José De Caldas (Contratos 430-2009 y 0313-2012) y del proyecto Ganadería Colombiana Sostenible financiado por el GEF-Banco Mundial y FAO-LEAD.
Parte de los resultados de este trabajo se analizaron en el marco de la tesis de maestría denominada "Diversidad y abundancia de larvas de Trichoptera (Insecta) asociadas a pequeñas quebradas andinas del centro y sur occidente de Colombia", llevada a cabo en el Posgrado de Biología de la Universidad de Costa Rica.

\section{RESUMEN}

Con el fin de determinar el impacto del uso del suelo sobre las características bióticas y abióticas de quebradas en la cuenca del río La Vieja, se evaluaron 21 quebradas en los municipios de Alcalá, Ulloa y Cartago (Valle del Cauca). Siete quebradas estaban protegidas por franjas de vegetación ribereña, ocho tenían influencia agrícola y seis influencia ganadera. Se registraron las condiciones de protección y perturbación del hábitat, aspectos físicos del cauce, se tomaron muestras de agua para análisis fisicoquímico y bacteriológico, y se recolectaron macroinvertebrados acuáticos. En las quebradas con influencia ganadera los sólidos disueltos, la alcalinidad, conductividad y fósforo total fueron significativamente mayores, mientras que el oxígeno disuelto fue significativamente menor. Las quebradas agrícolas y protegidas presentaron más sustratos gruesos y más tipos de corriente. Se recolectaron 26777 macroinvertebrados de 17 órdenes, 72 familias y 95 géneros. Los grupos con mayor abundancia relativa fueron Diptera $62.8 \%$, (Chironomidae 49.6\%, Ceratopogonidae $6.7 \%$ ), Mollusca $18.8 \%$ (Hydrobiidae 7.2\%, Sphaeriidae $9.6 \%$ ) y Trichoptera $5.7 \%$ (Hydropsychidae $3.7 \%$ ). Ephemeroptera, Trichoptera y Plecoptera, presentaron mayor abundancia en las quebradas protegidas y con influencia agrícola, mientras los dípteros y moluscos fueron más abundantes en las ganaderas. Las quebradas protegidas y agrícolas presentan mejores condiciones físicas y biológicas que las quebradas con influencia ganadera.

Palabras claves: quebradas andinas, biomonitoreo, insectos acuáticos, agricultura, ganadería.

\section{REFERENCIAS}

Alba-Tercedor, J. (1996). Macroinvertebrados acuáticos y calidad de las aguas de los ríos. VI Simposio del agua en Andalucía (SIAGA), 2, 203-213.

Allan, J. D. (2004). Landscapes and riverscapes: The influence of land use on stream ecosystems. Annual Review of Ecology, Evolution and Systematics, 35, 257-284.

APHA. (2005). Standard Methods for the examination of water and wastewaters, 21th edition. Washington: American Public Health Association. 
Baillie, B. R., \& Davies, T. R. (2002). Effects of land use on the channel morphology of streams in the Moutere Gravels, Nelson, New Zealand. Journal of Hydrology, 41, 19-45.

Barbour, M. T., Gerritsen, J., Snyder, B., \& Stribling, J. (1999). Rapid Bioassessment protocols for use in streams and wadeable rivers: periphyton, benthic macroinvertebrates and fish. U. S. Washington D.C.: Environmental Protection Agency, Office of Water.

Bonada, N., Prat, N., Resh, V. H., \& Statzner, B. (2006). Developments in aquatic insect biomonitoring: A comparative analysis of recent approaches. Annual Review of Entomology, 51, 495-523.

Braccia, A., \& Voshell, R. (2006). Benthic macroinvertebrate responses to increasing levels of cattle grazing in Blue Ridge mountain streams, Virginia, USA. Environmental Monitoring Assessment, 131, 185-200.

Bücker, A., Sondermann, M., Frede, H. G., \& Breuer, L. (2010). The influence of land-use on macroinvertebrate communities in montane tropical streams a case study from Ecuador. Fundamental and Applied Limnology, 177, 267-282.

CARDER (Corporación Autónoma Regional de Risaralda). (2007). Situación de los recursos naturales y el medio ambiente en Risaralda. Pereira, Colombia.

Calle, Z., \& Piedrahita, L. (2008). Conservación de la flora amenazada en fincas ganaderas de la cuenca media del río LaVieja. In E. Murgueitio, C. Cuartas \& J. F. Naranjo (Eds.), Ganadería del futuro: Investigación para el desarrollo (pp. 147-169). Cali: Fundación CIPAV.

Chará, J. (2004). Manual de evaluación biológica de ambientes acuáticos en microcuencas ganaderas. 2 ed. Cali: Fundación CIPAV.

Chará, J., Pedraza, G., Giraldo, L. P., \& Hincapié, D. (2007). Efecto de corredores ribereños sobre el estado de quebradas en la zona ganadera del río La Vieja, Colombia. Agroforestería de las Américas, 45, 72-78.

Chará, J., Pedraza, G., \& Giraldo, L. P. (2009). Corredores ribereños como herramienta de protección de Ambientes Acuáticos en zonas ganaderas. In E. Murgueitio, C. Cuartas \& J. F. Naranjo (Eds.), Ganadería del futuro: Investigación para el desarrollo (pp. 111130). Cali: Fundación CIPAV.

Chará, J. D., Giraldo, L. P., Zúñiga, M. del C., CharáSerna, A.M., \& Pedraza, G. X. (2011). Cambios en el ambiente acuático asociados a la restauración del corredor ribereño en una quebrada afectada por ganadería en la cuenca del río La Vieja, Colombia. In O. Vargas-Ríos \& S. P. Reyes (Eds.), La restauración ecológica en la práctica: Memorias I Congreso Colombiana de Restauración ecológica y II Simposio Nacional de Experiencias en Restauración Ecológica (pp. 564-572). Santafé de Bogotá, Colombia:
Universidad Nacional de Colombia-Sede Bogotá, Facultad de Ciencias, Departamento de Biología.

Collier, K., Wilcock, R., \& Meredith, A. (1998). Influence of substrate type and Physico-chemical conditions on macroinvertebrate faunas and biotic indices of some lowland Waikato, New Zeland, streams. New Zealand Journal of Marine and Freshwater Research, 32, 1-19.

Collins, R. (2003). Relationships between streamwater E. Coli concentrations and environmental factors in New Zealand. Diffuse Pollution Conference Dublin, 3, 176-180.

Di Rienzo, J.A., Casanoves, F., Balzarini, M.G., Gonzalez L., Tablada M., \& Robledo C.W. (2008). InfoStat, versión 2008, Grupo InfoStat, FCA. Argentina: Universidad Nacional de Córdoba.

Domínguez, E., Molineri, C., Pescador, M.L., Hubbard, M.D., \& Nieto, C. (2006). Ephemeroptera of South America. In J. Adis, J. R. Arias, G. Rueda-Delgado \& K. M. Wantzen (Eds.), Aquatic Biodiversity in Latin America (ABLA) (pp. 1-646). Vol. 2. Sofia-Moscow: Pensoft.

Domínguez, E., \& Fernández, H. R. (Eds.). (2009). Macroinvertebrados bentónicos sudamericanos. Sistemática y biología. Tucumán: Fundación Miguel Lillo.

Duehr, J. P., \& Siepker, M. J. (2006). Relation of Riparian Buffer Strips to In-Stream Habitat, Macroinvertebrates and Fish in a Small Iowa Stream. Journal of the Iowa Academy of Science, 113, 49-55.

Gamboa, M., Reyes, R., \& Arrivillaga, J. (2008). Macroinvertebrados bentónicos como bioindicadores de salud ambiental. Boletín de Malariología y Salud Ambiental, 48, 109-120.

Giraldo, L. P., Chará, J. D., Zúñiga, M. del C., Pedraza, G. X., \& Chará-Serna, A. M. (2011). Efectos de los corredores ribereños sobre características biótica y abióticas de quebradas ganadera en la cuenca del río La Vieja, Colombia. In O. Vargas-Ríos \& S. P. Reyes (Eds.), La restauración ecológica en la práctica: Memorias I Congreso Colombiano de Restauración ecológica y II Simposio Nacional de Experiencias en Restauración Ecológica (pp. 583-591). Santafé de Bogotá: Universidad Nacional de Colombia-Sede Bogotá, Facultad de Ciencias, Departamento de Biología.

Hall, M., Closs, G., \& Riley, R. (2001). Relationships between land use and stream invertebrate community structure in a South Island, New Zealand, coastal stream catchment. New Zealand Journal of Marine and Freshwater Research, 35, 591-603.

Harding, J. S., Benfield, E. F., Bolstad, P. V., Helfman, G. S., \& Jones, E. B. D. (1998). Stream biodiversity: The ghost of land use past. Proceedings of the National Academy of Sciences, 95, 4843-14847. 
Heartsill-Scalley, T., \& Aide, T. (2003). Riparian vegetation and stream condition in a tropical agriculturesecondary forest mosaic. Ecological Applications, 13, 225-234.

Herbst, D. B., Bogan, M. T., Roll, S. K., \& Safford, H. D. (2012). Effects of livestock exclusion on in-stream habitat and benthic invertebrate assemblages in montane streams. Freshwater Biology, 57, 204-217.

Laurence, W. F., Didham, R. K., \& Power, M. E. (2001). Ecological boundaries: a search for synthesis. Trends in Ecology and Evolution, 16, 70-71.

Leps, J., \& Smilauer, P. 2003. Multivariate analysis of ecological data using CANOCO. United Kingdom: Cambridge University press.

Lorion, C., \& Kennedy, B. (2009). Relationships between deforestation, riparian forest buffers and benthic macroinvertebrates in neotropical headwater streams. Freshwater Biology, 54, 165-180.

Méndez, L. E., \& Calle, Z. (2010). Plantas de la Cuenca media del río La Vieja. Cali: CIPAV y CIEBEREG.

Miserendino, M. L., \& Masi, C. I. (2010). The effects of land use on environmental features and functional organization of macroinvertebrate communities in Patagonian low order streams. Ecological Indicators, 10,311-319

Monaghan, R. M., Carey, P. L., Wilcock, R. J., Drewry, J. J., Houlbrooke, D. J., Quinn, J. M., \& Thorrold, B. S. (2009). Linkages between land management activities and stream water quality in a border dykeirrigated pastoral catchment. Agriculture, Ecosystems and Environment, 129, 201-211.

Moore, R. D., \& Richardson, J. (2003). Progress towards understanding the structure, function and ecological significance of small stream channels and their riparian zone. Canadian Journal of Forestry Research, $33,1349-1351$

Moya, N., Oberdorff, T., Bigorne, R., Zubieta, J., \& Camacho, J. (2006). Comunidad de macroinvertebrados en ríos de la cuenca Chipiriri con condiciones de referencia y alteradas, estudio preliminar para la bioevaluación de arroyos. Ciencia abierta Internacional, $30,1-27$

Murgueitio, E., \& Ibrahim, M. (2009). Ganadería y media ambiente en América Latina. In E. Murgueitio, C. Cesar \& J. F. Naranjo (Eds.), Ganadería del futuro, Investigaciones para el desarrollo (pp. 20-39). Cali: Fundación CIPAV.

Nakamura, F., \& Yamada, H. (2005). Effects of pasture development on the ecological functions of riparian forests in Hokkaido in northern Japan. Ecological Engineering, 24, 539-550.

Naiman, R.J., Decamps, H., \& McClain, M. E. (2005). Riparia: Ecology, Conservation, and Management of Streamside Communities. London: Elsevier Academic Press.

Piscart, C., Genoel, R., Doledec, S., Chauvet, E., \& Marmonier, P. (2009). Effects of intense agricultural practices on heterotrophic processes in streams. Environmental Pollution, 157, 1011-1018.

Posada, J., Roldán, G., \& Ramírez, J. (2000). Caracterización físicoquímica y biológica de la calidad de aguas de la cuenca de la quebrada Piedras Blancas, Antioquia, Colombia. Revista Biología Tropical, 48, 59-70.

Posada, J., \& Roldán, G. (2003). Clave ilustrada y diversidad de las larvas de Trichoptera en el noroccidente de Colombia. Caldasia, 25, 169-192.

Quinn, J. M., Boothroyd, I. K. G., \& Smith, B. J. (2004). Riparian buffers mitigate effects of pine plantation logging on New Zealand streams 2. Invertebrate communities. Forest Ecology and Management, 191, 129-146.

Richards, C., \& Host, G. (1994). Examining land use influences on stream habitats and macroinvertebrates: A GIS approach. American Water Resources Association, 30, 729-738.

Rios, S. L., \& Bailey, R.C. (2006) Relationship between riparian vegetation and stream benthic communities at three spatial scales. Hydrobiologia, 553, 153-160.

Riseng, C. M., Wiley, M. J., Black, R. W., \& Munn, M. D. (2011). Impacts of agricultural land use on biological integrity: a causal analysis. Ecological Applications, 21, 3128-3146.

Roldán, G. (2003). Bioindicación de la calidad del agua en Colombia: Uso del método BMWP/Col. Medellín: Editorial Universidad de Antioquia.

Sadeghian, S., Rivera, J., \& Gómez, M. (1999). Impacto de sistemas de ganadería sobre las características físicas, químicas y biológicas de suelos en los Andes de Colombia. In M. Sánchez \& M. Rosales (Eds,), Agroforestería para la Producción Animal en América Latina (pp. 123-142). Roma, IT: FAO (Producción y Sanidad Animal No. 143).

Schlosser, I. (1991). Stream Fish Ecology: A Landscape Perspective. BioScience, 41, 704-712.

Stark, B. P., Froehlich, C., \& Zúñiga, M. del C. (2009). South America Stoneflies (Plecoptera). In J. Adis, J. R. Arias, S. Golovatch, K.M. Wantzen \& G. RuedaDelgado (Eds.), Aquatic Biodiversity in Latin Ameri$c a$ (ABLA). Sofia-Moscow: Pensoft.

Sovell, L., Vondracek, B., Frost, J., \& Mumford, K. (2000). Impacts of rotational grazing and riparian buffers on physicochemical and biological characteristics of southeastern Minnnesota, streams. Environmental Management, 26, 629-641.

Ter Braak, C. J. R., \& Smilauer, P. (1997). Canoco for Windows version 4.0. The Netherlands: Centre for Biometry Wagenigen. 
Thomas, S., Neill, C., Deegan, L., Krusche, A., Ballester, V., \& Victoria, R. (2004). Influences of land use and stream size on particulate and dissolved materials in a small Amazonian stream network. Biogeochemistry, 68, 135-151.

Winckler-Sosinski, L. T., Silveira, T. C. L., Schulz, U. H., \&. Schwarzbold, A. (2008). Interactions between benthic macroinvertebrates and fishes in a low order stream in Campos de Cima da Serra, RS, Brazil. Brazilian Journal of Biology, 68, 695-701.
Wohl, E. (2006). Human impacts to mountain streams. Geomorphology, 79, 217-248.

Zúñiga, M. del C. (2010). Diversidad, distribución y ecología del orden Plecoptera (Insecta) en Colombia, con énfasis en Anacroneuria (Perlidae). Momentos de Ciencia, 7, 101.

Zúñiga, M. del C., \& Cardona, W. (2009). Bioindicadores de calidad de agua y caudal ambiental. In J. Cantera, J. Carvajal \& L. M. Castro (Eds.), Caudal ambiental: conceptos, experiencias y desafios (pp. 167-197). Cali: Programa editorial de la Universidad del Valle. 
